\title{
A longitudinal study of back pain and radiological changes in the lumbar spines of middle aged women. I. Clinical findings
}

\author{
D P M Symmons, A M van Hemert, J P Vandenbroucke, H A Valkenburg
}

\begin{abstract}
The natural history of low back pain was evaluated over a nine year period in two groups of middle aged Dutch women selected from the general population. One group had recurrent back pain $(n=236)$ and the other group had never experienced back pain $(n=241)$. At the onset of the study recurrent back pain was associated with smoking, previous use of the 'pill', pain in other joints, frequent headaches, and restricted lumbar spine movement. Nine years later $170(72 \%)$ of the group with back pain had continuing pain and $58(24 \%)$ of the group without previous back pain had incident pain. Pain in other joints, especially the hip and knee, was a predictor of continuing and incident pain but age, body mass index, and smoking were not.
\end{abstract}

Back pain is one of the most common medical problems in the Western world. In people aged 45-64 it ranks third after heart disease and the category of 'arthritis and rheumatism' as a cause of limited activity. ${ }^{1}$ A population based study from Sweden found that $67 \cdot 2 \%$ of women aged 45-64 have a past history of back pain-many on numerous occasions. ${ }^{2}$ The prevalence in men is similar. ${ }^{3}$ Potential risk factors for the development of back pain include cigarette smoking, ${ }^{3} 4$ multiparity, ${ }^{4}$ driving motor vehicles, ${ }^{3}$ and repetitive lifting. ${ }^{5}$ Emotional and psychological difficulties are common among those with back pain, ${ }^{6}$ but whether this is the cause or the effect of the symptoms is unclear. Educational status, degree of job satisfaction, and income are all related to the functional disability caused by back pain. ${ }^{7}$

What happens to all these people with back pain? Do they continue to have pain for the rest of their lives? Can one predict who will develop back pain for the first time? In the short term (up to one year) previous low back symptoms are a highly significant predictor of future symptoms. ${ }^{8-10}$ There are, however, few studies of the long term prognosis of back pain in the general population. To remedy this situation we conducted a longitudinal study of back pain in a group with a particularly high prevalence of back pain-middle aged women.

It is impossible to establish the cause of back pain in most acute episodes ${ }^{11}$ and in up to $50 \%$ of chronic cases. ${ }^{12}$ In population studies it is, therefore, probably best to regard back pain as a single symptom complex rather than to attempt to subdivide the sufferers into causal groups.

\section{Subjects and methods}

INITIAL POPULATION SURVEY

A population survey of rheumatic and cardiovascular diseases was conducted in Zoetermeer, a suburb of The Hague, between 1975 and $1978 .^{13}$ Respondents were assessed by means of a self-administered questionnaire* which covered past medical history, rheumatic and back complaints, headaches, menstrual complaints, drugs, and smoking habits. Physical examination included measurement of height, weight, blood pressure, spinal movements, and calculation of the body mass index (BMI) (weight/height ${ }^{2}$ ).

\section{FOLLOW UP SURVEY}

A follow up survey was conducted in 1985-6. Its prime aim was to investigate risk factors for the development of postmenopausal osteoporosis and so only middle aged women were included. The initial survey had included 1167 women aged 45-64 (response rate $78 \%$ ). Nine years later 71 had died and 87 had moved away from the area. The remaining 1009 women were invited to participate in the follow up study. This second survey consisted of a self-administered questionnaire* which covered back complaints, drugs including hormone replacement, gynaecological and reproductive history, current smoking habits, and the occurrence of falls. Respondents attended for measurement of height and weight. By the end of 1986 full details were available on 742 women $(74 \%)$. The present analysis concerns two subgroups of these women. The first $(n=241)$ had said, in the 1975-8 survey, that they had never had back pain. The second group with recurrent back pain $(n=236)$ had responded positively to all of the following three questions: 'Are you suffering from back pain now?' 'Have you suffered from back pain in the past?' 'Have you had back pain more than once in the past?'

\section{RADIOLOGICAL ASSESSMENT}

The lumbar spine radiographs of the above 477 women were read for the presence of disc degeneration and osteoporotic vertebral collapse without knowledge of the subject's identity or medical history. Full details of the methods and results of the radiological assessment are presented in the accompanying paper. ${ }^{14}$

\section{STATISTICS}

Relative risks (RR) and test-based $95 \%$ confidence intervals (CI $)^{15}$ were used to assess the 
differences between the groups with and without back pain, and between the symptomatic and asymptomatic women at follow up. Predictors of pain in 1985-6 were assessed with the BMDP programme for stepwise logistic regression. ${ }^{16}$

\section{Results}

COMPARISON IN 1975-8 OF THE GROUPS WITH AND WITHOUT BACK PAIN

The mean age, height, weight, BMI, systolic and diastolic blood pressure were comparable between the two groups at the start of the study (table 1). A similar proportion of women in both groups were postmenopausal (table 2). A higher proportion of the group with back pain had taken the oral contraceptive pill. Menstrual irregularity and pain did not differ between the groups. Smoking (both past and present) was significantly more common in the subjects with

Table 1 Demographic features of the groups with recurrent back pain $(R B P)$ and no back pain (NBP) in 1975-8 and 1985-6

\begin{tabular}{|c|c|c|c|c|}
\hline & \multicolumn{2}{|c|}{$\begin{array}{l}R B P \\
(n=236)\end{array}$} & \multicolumn{2}{|c|}{$\begin{array}{l}N B P \\
(n=241)\end{array}$} \\
\hline & Mean & $S D$ & Mean & $S D$ \\
\hline $\begin{array}{l}1975-8 \\
\text { Age (years) } \\
\text { Height (m) } \\
\text { Weight (kg) } \\
\text { BMI (kg/m }) \\
\text { Systolic BP (mmHg) } \\
\text { Diastolic BP (mmHg) }\end{array}$ & $\begin{array}{l}53 \cdot 8 \\
1 \cdot 61 \\
67 \cdot 3 \\
25 \cdot 3 \\
133 \cdot 4 \\
86 \cdot 3\end{array}$ & $\begin{array}{l}5 \cdot 7 \\
0 \cdot 16 \\
11 \cdot 4 \\
4 \cdot 9 \\
21 \cdot 8 \\
13 \cdot 3\end{array}$ & $\begin{array}{c}54 \cdot 2 \\
1 \cdot 62 \\
67 \cdot 2 \\
25 \cdot 2 \\
134 \cdot 7 \\
86 \cdot 8\end{array}$ & $\begin{array}{r}5 \cdot 7 \\
0 \cdot 11 \\
10 \cdot 7 \\
4 \cdot 2 \\
19 \cdot 4 \\
11 \cdot 8\end{array}$ \\
\hline $\begin{array}{l}1985-6 \\
\text { Age (years) } \\
\text { Height (m) } \\
\text { Weight (kg) }\end{array}$ & $\begin{array}{c}62 \cdot 7 \\
1 \cdot 61 \\
69 \cdot 3\end{array}$ & $\begin{array}{c}5 \cdot 8 \\
0 \cdot 14 \\
10 \cdot 6\end{array}$ & $\begin{array}{c}63 \cdot 2 \\
1 \cdot 61 \\
68 \cdot 1\end{array}$ & $\begin{array}{c}5 \cdot 8 \\
0 \cdot 12 \\
11 \cdot 4\end{array}$ \\
\hline
\end{tabular}

Table 2 Comparison of the groups with recurrent back pain (RBP) and no back pain $(N B P)$ in $1975-8$

\begin{tabular}{|c|c|c|c|}
\hline & $\begin{array}{l}R B P \\
\text { No }(\%)\end{array}$ & $\begin{array}{l}\text { NBP } \\
\text { No (\%) }\end{array}$ & $R R^{*}\left(95 \% C I^{*}\right)$ \\
\hline $\begin{array}{l}\text { Current smoker } \\
\text { Ever smoked } \\
\text { Ever taken 'pill' } \\
\text { Postmenopausal }\end{array}$ & $\begin{array}{r}93(39) \\
148(63) \\
74(31) \\
166(70)\end{array}$ & $\begin{array}{r}47(20) \\
117(49) \\
46(19) \\
160(66)\end{array}$ & $\begin{array}{l}1.57(1.30 \text { to } 1.89) \\
1.35(1.12 \text { to } 1.63) \\
1.36(1.12 \text { to } 1.65) \\
1.10(0.90 \text { to } 1.35)\end{array}$ \\
\hline $\begin{array}{l}\text { Medical history } \\
\text { Joint pains } \\
\text { Hip/knee gelling } \\
\text { Hip/knee pain on standing } \\
\text { Weekly headaches } \\
\text { Cystitis }\end{array}$ & $\begin{array}{r}191(81) \\
106(45) \\
90(38) \\
84(36) \\
140(59)\end{array}$ & $\begin{array}{r}94(39) \\
28(12) \\
22(9) \\
30(12) \\
104(43)\end{array}$ & $\begin{array}{l}2.86(2.29 \text { to } 3.57) \\
2.09(1.75 \text { to } 2.50) \\
2.00(1.67 \text { to } 2.40) \\
1.76(1.46 \text { to } 2.12) \\
1.41(1.17 \text { to } 1.70)\end{array}$ \\
\hline $\begin{array}{l}\text { Examination } \\
\text { Limited rotation } \\
\text { Neurological } \\
\text { Kyphosis } \\
\text { Limited flexion } \\
\text { Heberden's nodes }\end{array}$ & $\begin{array}{l}45(19) \\
10(4) \\
28(12) \\
47(20) \\
31(13)\end{array}$ & $\begin{aligned} 16 & (7) \\
1 & (0 \cdot 4) \\
15 & (6) \\
21 & (9) \\
29 & (12)\end{aligned}$ & $\begin{array}{l}1.61(1.28 \text { to } 2.03) \\
1.87(1.21 \text { to } 2.90) \\
1.56(1.21 \text { to } 2.01) \\
1.50(1.20 \text { to } 1.88) \\
1.05(0.81 \text { to } 1.37)\end{array}$ \\
\hline
\end{tabular}

${ }^{*} \mathrm{RR}=$ relative risk; $\mathrm{CI}=$ confidence interval.

Table 3 Comparison of the groups with recurrent back pain (RBP) and no back pain $(N B P)$, at follow up (1985-6)

\begin{tabular}{lccc}
\hline & $R B P$ & $N B P$ & $R R^{*}\left(95 \% C^{*}\right)$ \\
& $N o(\%)$ & No $(\%)$ & \\
\hline Oestrogen use & $89(38)$ & $56(23)$ & $1 \cdot 39(1 \cdot 15$ to $1 \cdot 68)$ \\
Hysterectomy & $65(28)$ & $50(21)$ & $1 \cdot 20(0.98$ to $1 \cdot 47)$ \\
Current smoker & $60(25)$ & $55(23)$ & $1.07(0.88$ to $1 \cdot 31)$ \\
Postmenopausal & $236(100)$ & $100(100)$ & 1.00 \\
\hline
\end{tabular}

back pain, as was a past history of cystitis and a current history of frequent headaches (at least once a week). The subjects with back pain also had a higher prevalence of pain in other joints.

Abnormalities of spinal movement and contour were more common in, but not confined to, those with back pain. All of the group with back pain had difficulties in performing their household duties and $13(5 \cdot 5 \%)$ had changed their jobs because of the pain. One hundred and twenty eight (54\%) had had back pain for more than three months continuously and $108(46 \%)$ had needed to resort to bed rest.

\section{COMPARISON IN 1985-6 OF THE GROUPS WITH AND} WITHOUT BACK PAIN

The mean follow up period was 8.7 years. At the second survey there was again little difference in the mean height, weight, BMI, systolic or diastolic blood pressure between the two groups. All subjects were now postmenopausal. Among the group with back pain oestrogen use was more common (table 3 ). The number of smokers in the group with back pain had fallen considerably.

\section{CHANGE IN SYMPTOMS}

At the time of the second questionnaire 170 (72\%) of the group with recurrent back pain and $58(24 \%)$ of the group without previous back pain stated that they were experiencing back pain then or had experienced continuous back pain for more than two weeks in the follow up period. Recurrent back pain in 1975-8 was thus a strong predictor for back pain in 1985-6 ( $R R=2 \cdot 99 ; 95 \%$ CI $2 \cdot 45$ to $3 \cdot 67$ ).

Univariate analysis showed no associations between continuing pain in the group with recurrent back pain and the following features as recorded in 1975-8: age, BMI, smoking, multiparity, bed rest owing to back pain, sciatica, kyphosis, or limited spinal movement (table 4). Neither the presence of radiological disc degeneration nor of osteoporotic fractures in 1975-8 was a predictor of continuing pain. Continuing pain was not related to deterioration of disc degeneration or to incident fractures in the follow up period. Hormone replacement therapy in the follow up period had no effect on

Table 4 Predictors of continuing pain in the group with recurrent back pain*

\begin{tabular}{ll}
\hline Univariate analysis & $R R t(95 \%$ CI $f)$ \\
\hline Joint pains & $1.33(1.05$ to 1.68$)$ \\
Hip/knee pain on standing & $1.28(1.09$ to 1.50$)$ \\
Falls 1978-1985 & $1.23(1.05$ to 1.45$)$ \\
Weekly headaches & $1.19(1.01$ to 1.40$)$ \\
Hip/knee gelling & $1.17(1.01$ to 1.37$)$ \\
Limited flexion & $1.06(0.92$ to 1.23$)$ \\
Deterioration of disc degeneration & \\
$\quad$ 1978-85 & $1.03(0.86$ to 1.23$)$ \\
Smoker & $1.03(0.85$ to 1.25$)$ \\
Hormone replacement therapy & $1.01(0.91$ to 1.13$)$ \\
Limited rotation & $0.98(0.76$ to 1.27$)$ \\
Osteoporotic fracture & $0.91(0.72$ to 1.15$)$ \\
Disc degeneration & $0.88(0.76$ to 1.02$)$ \\
Kyphosis & $0.88(0.68$ to 1.14$)$ \\
\hline *Except where &
\end{tabular}

Except where otherwise stated these figures refer to factors detected by the first questionnaire (1975-8)

${ }^{*} \mathrm{RR}=$ relative risk; $\mathrm{CI}=$ confidence interval. 
Table 5 Predictors of incident pain in the group with no previous back pain*

\begin{tabular}{ll}
\hline Univariate analysis & $R R t(95 \%$ CIf $)$ \\
\hline Hip/knee gelling & $2.65(1.62$ to 4.33$)$ \\
Joint pains & $2.56(1.64$ to 4.00$)$ \\
Hip/knee pain on standing & $2.07(1.16$ to 3.69$)$ \\
Limited rotation & $1.93(0.83$ to 3.79$)$ \\
Hormone replacement therapy & $1.54(0.97$ to 2.45$)$ \\
Incident osteoporotic fracture & $1.52(0.82$ to 2.81$)$ \\
Osteoporotic fracture 1975-8 & $1.42(0.87$ to 2.32$)$ \\
Kyphosis & $1.42(0.64$ to 3.14$)$ \\
Deterioration of disc degeneration & $1.03(0.63$ to 1.69$)$ \\
$\quad$ Weekly headaches & 1.00 \\
Limited flexion & $0.99(0.50$ to 1.96$)$ \\
Smoker & $0.78(0.47$ to 1.30$)$ \\
\hline
\end{tabular}

${ }^{*}$ Except where otherwise stated these figures refer to factors .

$+R R=$ relative risk; $C I=$ confidence interval.

continuing pain. There was, however, a positive association between continuing back pain and pain in other joints, pain in the hip or knee on standing, gelling of the hip or knee on sitting, and a history of falls in the follow up period. Multivariate analysis using stepwise logistic regression with all these positively associated variables plus age in the model showed that pain in the hip or knee on standing was the only independent significant predictor of continuing pain (adjusted odds ratio $=2 \cdot 12 ; 95 \%$ CI 1.09 to $4 \cdot 15 ; \mathrm{p}=0.03)$.

Risk factors for the development of incident pain in the group without previous pain showed a similar pattern to those for continuing pain (table 5). Thus incident pain was unrelated to age, BMI, smoking, multiparity, or abnormalities of spinal movement or contour as measured in 1975-8. The presence of radiological disc degeneration or osteoporotic fractures in 1975-8 was not related to future pain, nor was the development or deterioration of disc degeneration or incident fractures in the follow up period. Again the only positive association was with pain in other joints, pain in the hip or knee on standing, and gelling of the hip or knee on sitting. Stepwise logistic regression showed that joint pain elsewhere was the only independent significant predictor of incident pain (adjusted odds ratio $=2 \cdot 72 ; 95 \%$ CI $1 \cdot 38$ to $5 \cdot 37$; $\mathrm{p}=0.005$ ).

\section{Discussion}

Chronic back pain is indeed a common problem in middle aged women. These figures, showing one third of women aged 45-64 with recurrent back pain and one third with no past history of back symptoms, are similar to those found in other population surveys. ${ }^{23}$

An association between cigarette smoking and back pain has been reported previously both in men $^{316}$ and women. ${ }^{4}$ Two explanations have been offered for this association. One is that smoking is associated with chronic coughing, ${ }^{4}$ which is the direct cause of the pain, and the other is that smoking may be correlated with vertebral osteoporosis. ${ }^{17}$ If the cough hypothesis were correct one would expect both incident and continuing back pain to be more common in those who continued to smoke during the follow up period. This was not, however, the case. When all 477 women were considered in 1985-6 there was no significant association between current smoking habits and current back pain ( $R R=1.02 ; 95 \%$ CI 0.89 to $1 \cdot 16)$. This loss of association between smoking and back pain with time is intriguing and worthy of further investigation.

Much attention has been focused in the past on occupational risk factors and back pain. 5 18 19 In our study of middle aged women only 116 (24\%) had ever worked (56 (24\%) of the group with back pain and $60(25 \%)$ of the group without back pain). Occupational factors were not, therefore, analysed further. The association between recurrent back pain and oral contraceptive use has not been described previously. The mechanism may either be hormonal or due to psychosocial factors influencing not only oral contraceptive use but also back symptoms.

Women with recurrent back pain more commonly had pain in other joints, particularly the hip and knee, and pain or gelling after sitting. These symptoms were also predictive of both continuing and incident pain. This raises the possibility that these women have osteoarthritis of the apophysial joints (which cannot be assessed adequately on a lateral radiograph). Spinal osteoarthritis is often associated with generalised osteoarthritis, ${ }^{20}$ but is independent of disc degeneration. Against this theory is the failure to find an increased prevalence of Heberden's nodes in the group with back pain (table 2).

Biering-Sorensen found that members of the general population have a high incidence of headaches, abdominal discomfort, and other complaints before and after the development of back trouble. ${ }^{21}$ Thus these women may be psychologically predisposed to the development of pain. ${ }^{22}$ This theory is supported by our confirmation of the association between frequent headaches and back pain.

As far as we know this is the first long term follow up study of back complaints in the general population. The strongest predictor of future back pain was symptoms in the past. One year follow up studies in the general population ${ }^{8}$ and from general practice ${ }^{10}$ have also found previous episodes of back pain, particularly if recurrent and of long duration, to be important prognostic indicators. In our study nearly three quarters of women who had experienced three or more episodes of back pain by 1975-8 still had back pain nine years later. Treatment of chronic back pain is notoriously unsatisfactory. ${ }^{23}$ Perhaps, in addition to advice on posture, relaxation, and exercises, women undergoing a second attack of non-specific back pain should be offered psychological assistance in understanding and modifying their response to pain.

Radiology was found to be of no value in predicting future episodes of back pain. Previous studies have shown that the radiograph has little to offer in the diagnosis of non-specific back pain in either the acute or chronic phase, ${ }^{23} 24$ except in the presence of certain sinister features. Our study suggests that the radiograph is of little help in offering a prognosis to those with chronic back pain. In particular, there seems to be no indication for repeat radiographs in this group of subjects. 
1 Kelsey J L, White A A. Epidemiology and the impact of low back pain. Spine 1980; 5: 133-42.

2 Hirsch C, Jonsson B, Lewin T. Low back symptoms in a Swedish female population. Clin Orthop 1969; 63: 171-6.

3 Frymoyer J W, Pope M H, Clements J H, Wilder D G, MacPherson B, Ashikaga T. Risk factors in low back pain. An epidemiological study. $\mathcal{f}$ Bone foint Surg [Am] 1983; A5: 213-8.

4 Frymoyer J W, Pope M H, Costanza M C, Rosen J C, Goggin J E, Wilder D G. Epidemiologic studies of back pain. Spine 1980; 5: 419-23.

5 Damkot D K, Pope M H, Lord J, Frymoyer J W. The relationship between work history, work environment and low back pain in men. Spine 1984; 9: 395-9.

6 Nagi S Z, Riley L E, Newby L G. A social epidemiology of back pain in a general population. $\mathcal{F}$ Chronic Dis 1973; 26: 769-79.

7 Deyo R A, Tsui-Wu Y-J. Functional disability due to back pain: a population-based study indicating the importance of socio-economic factors. Arthritis Rheum 1987; 30: 1247-53.

8 Biering-Sorensen F. A prospective study of back pain in a general population. Scand F Rehabil Med 1983; 15: 71-9.

9 Gyntelberg $F$. One year incidence of low back pain among yntelberg F. One year incidence of low back pain among 1974; 21 : 30-6.

10 Pedersen P A. Prognostic indicators in low back pain. $\mathcal{F} R$ Coll Gen Pract 1981; 31: 209-16.

11 Dillane J B, Fry J, Kalton G. Acute back syndrome-a study from general practice. $\mathrm{Br} \mathrm{Med} \mathcal{F} 1966$; ii: $82-4$.

12 Pope M H, Rosen J C, Wilder D G, Frymoyer J W. The relation between biomechanical and psychological factors in patients with low back pain. Spine 1980; 5: 173-8.

13 Valkenburg H A, Haanen H C M. The epidemiology of low back pain. In: White A, Gordon S L, eds. Symposium on idiopathic low back pain. Miami: Mosby, 1980: $9-22$.

14 Symmons D P M, van Hemert A M, Vandenbroucke J P Valkenburg $\mathbf{H}$ A. A longitudinal study of back pain and radiological changes in the lumbar spines of middle aged women. II. Radiographic findings. Ann Rheum Dis 1991; 50: $162-6$.

15 Miettinen $\mathrm{O}$ S. Estimability and estimation in case-referrent studies. Am f Epidemiol 1976; 103: 226-35.

16 Engelman L. Stepwise logistic regression. In: Dixon W J, ed. $B M D P$ statistical software. Berkeley: University of $B M D P$ statistical software.
California Press, 1983: $330-4$.

17 Svensson H-O, Vedin A, Wilhelmsson C, Andersson G B J. Low-back-pain in relation to other diseases and cardiovascular risk factors. Spine 1983; 8: 277-85.

18 Rowe M L. Low back pain in industry. A position paper. f Occup Med 1969; 11: 161-9.

19 Troup J D G, Martin J W, Lloyd D C E F. Back pain in industry. A prospective study. Spine 1981; 6: 61-9.

20 Kellgren J H, Lawrence J S. Osteoarthrosis and disk degeneration in an urban population. Ann Rheum Dis 1958; 17: 388-96.

21 Biering-Sorensen F, Thomsen C. Medical, social and occupational history as risk indicators for low back trouble in the tional history as risk indicators for low back

22 Frymoyer JW, Rosen J C, Clements J, Pope M H. Psychologic factors in low-back-pain disability .Clin Orthop 1985; 195: 178-84.

23 Frymoyer J W. Back pain and sciatica. $N$ Engl f Med 1988; 318: 291-300.

24 Liang M, Komaroff A L. Roentgenograms in primary care patients with acute low back pain: a cost-effective analysis. Arch Intern Med 1982; 142: 1108-12. 